The Present Status of

\section{Cardiac Surgery}

The numerous reports appearing in current British, American and French journals testify to the interest aroused by recent advances in cardiac surgery. It may, therefore, be helpful to recall certain landmarks in its history and to review the present status of those procedures which have proved of value.

\section{Congenital Heart Disease}

Although the surgical treatment of pulmonary stenosis is now soundly established it is well to recall that until 1944 these cases were of interest only to the morbid anatomist. Many types of congenital cardiac deformities had been described, but it was only when Helen Taussig realized that the essential abnormality in cyanotic children was a deficient blood flow from heart to lungs that therapeutic interest was aroused. With Taussig's support Blalock (1946) devised the operation of systemic-pulmonary anastomosis, since named after him. This increases pulmonary blood flow, alleviates the crippling disability and transforms the life of these pathetic children. This advance stimulated interest in the surgical treatment of heart disease and cardiologists began to assess the operability of an unsuspected backlog of thousands of similar cases.

Congenital deformities account for 2.5 per cent. of heart disease. The principal abnormalities occur in the pulmonary outflow tract and include pure pulmonary stenosis and the tetralogy of Fallot. Untreated the prognosis is grave. In pure pulmonary stenosis the obstruction is nearly always at the valve, there is no ventricular septal defect, and cyanosis, if it occurs, is due to a patent foramen ovale. Right ventricular pressure is high and sudden right-sided heart failure a constant threat. Though the diagnosis of pure pulmonary stenosis is difficult clinically, it may be made on catheterization of the heart when the right ventricular pressure may be shown to be higher than the systemic pressure, or by angiocardiography when the over-riding aorta and rapid ventricular emptying of the tetralogy are absent. Pulmonary valvotomy* through the right ventricle by the technique of Brock (1948) and Sellors (1948) is the treatment of choice. Systemic-pulmonary anastomosis is dangerous as it does nothing to relieve the strain on the right ventricle and adds to that on the left.

In the more common tetralogy of Fallot the stenosis may be infundibular or valvular or occasionally both. The narrowing of the outflow tract and the ventricular septal defect diminish pulmonary blood flow and cyanosis is present to a varying degree. Diagnosis is relatively easy. Valvotomy relieves the valvular stenosis and the low infundibular stenosis may be resected. Unfortunately a general infundibular hypoplasia is often present or a high subvalvular obstruction occurs too near a normal pulmonary valve to be divided with a valvotome. For these an extracardiac systemic-pulmonary anastomosis should be done. In general, valvotomy is indicated for valvular stenosis and recent reports suggest that in experienced hands the operative mortality is less than that of the Blalock procedure. When the latter procedure is indicated in infants and io other cases where a high aortic arch and show subclavian artery prevent a subclavian-pulmonary anastomosis, the Potts aortic-pulmonary anastomosis is indicated. In most cases the results of these operations for pulmonary stenosis have been immediately good, but in a proportion the improvement has not been fully apparent for some months until the pulmonary outflow tract and arteries have enlarged to accommodate the increasing blood flow.

Other common abnormalities amenable to surgical correction include patent ductus arteriosus and coarctation of the aorta. Although cardiologists are not yet unanimous as to the indications for ligation of a patent ductus arteriosus, it is incontrovertible that the average life expectancy of the patient is shorter than normal. The most urgent indication is bacterial endocarditis as Tubbs (1944), who tied the first infected ductus in 1938, has shown. Others include cardiac failure, under-development and pulmonary hypertension.

* The term 'valvulotomy' should be replaced by the original and more correct 'valvotomy.' 
As the cardiac output is raised even at rest the wear and tear is ultimately bound to be greater than normal. Fifty per cent. die by the age of $30 ; 25$ per cent. develop endocarditis. The operation is usually easy, an occasional difficulty being due to a wide short ductus for which division and closure of the ends is required in place of simple ligation; the mortality is almost nil below the age of three years.

By contrast the surgical correction of coarctation of the aorta is a difficult procedure. Despite this it should be advised for all patients below 30 years of age who have large hearts, a rising blood pressure or complications. Asymptomatic adults appear to have a reasonably good prognosis without operation. As with ligation of a patent ductus the mortality is low in younger patients. Gross (195I) has recently reported the use of preserved aortic segments in 19 cases in which resections left a long gap requiring insertion of a graft to bridge the defect. Grafting has other applications and is made much easier by the formation of a blood vessel bank.

\section{Constrictive Pericarditis}

In constrictive pericarditis, pericardectomy to release the heart may produce marked improvement. There is an increasing tendency to operate early, under streptomycin cover, in young patients with a history of tuberculous pericarditis. In the older, chronic group the extent of the heart or liver damage influences the prognosis.

\section{Mitral Stenosis}

Undoubtedly the greatest advance in the surgery of the heart is the relief of the disabilities and poor prognosis of mitral stenosis. Surgical treatment of congenital deformities benefits those who are young; the correction of mitral stenosis aids those in the prime of life who are of greater value to the community as mothers, bread-winners and artisans. It has been estimated that 25 per cent. of heart disease is of rheumatic origin and conservative estimates have indicated an incidence of 5,000 cases of mitral stenosis per million population. The problem today is not the selection of cases suitable for operation but the provision of adequate facilities to cope with the ever-growing waiting lists. The magnitude of the problem is 气 not simply one of numbers, but the fact that a $\frac{2}{\mathbb{D}}$ significant proportion of cases of mitral stenosis die whilst awaiting surgery.

Sir Lauder Brunton proposed an operation for the relief of mitral stenosis half a century ago, but the first operations on the stenosed valve were performed by Allen (1922) and Cutler (1929) in the United States and by Souttar (1925) in this country. These failed because of inadequate $\vec{\circ}$ knowledge and experience of thoracic surgery. Meanwhile in the past 15 years advances in thoracic surgery and in anaesthesia, the advent of antibiotics and muscle-relaxants, and success in the operative correction of congenital deformities led $\infty$ to a renewed and successful approach by Bailey and Harken in America and by Brock in this country.

Surgical treatment should be considered for the majority of cases of mitral stenosis, but there are $\vec{c}$ certain general indications and contraindications. The principal indication for valvotomy is disability, such as dyspnoea on exertion or inability to carry on a normal occupation. For severe orthopnoeक्ठ $\overrightarrow{0}$ cardiac asthma and pulmonary oedema valvotom 엉 should not be long delayed as these signs betoke threatening pulmonary hypertension. Auricular fibrillation, severe haemoptysis, frequent attacks of pulmonary oedema, emboli or recovery from congestive cardiac failure demand early operation. Contraindications to valvotomy are recent rheu- $\overrightarrow{\overrightarrow{0}}$ matic fever, severe mitral incompetence and a significant proportion of disability due to associated aortic diseases evidenced by electrocardiographic $\overline{0}$ and radiographic changes. Time may show that marked pulmonary hypertension contraindicates valvotomy, and the importance of permanent $\dot{\delta}$ changes in the pulmonary arteries has yet to be assessed. Age is important because patients below 은 20 run the risk of recrudescence of rheumatic $\frac{D}{O}$ myocarditis, but this danger has to be weighed agaist the severity of the symptoms or dangers of $\stackrel{N}{\circ}$ severe haemoptysis. In the majority the actual or $N$ potential myocarditis is over-shadowed by the $\underset{\omega}{N}$ mechanical obstruction.

Pregnancy causing complications is an indica- $\frac{0}{\Phi}$ tion for mitral valvotomy, not for hysterotomy. ? Caesarean section or early forceps delivery may be $\frac{T}{T}$ 
employed as an alternative but these cases need careful supervision in the post-natal period and early valvotomy if they deteriorate. Some cases with congestive failure from mitral stenosis may be considerably improved by ligation of the inferior vena cava, but valvotomy should be performed in the following 12 to 18 months before deterioration recurs.

The treatment of regurgitation is still in the experimental stage but both here and in America the insertion of a trans-ventricular pericardial flap below the mitral orifice has been successful.

The early results of mitral valvotomy have been dramatic in the majority of cases. Most patients are restored to an active life and enabled to recommence their previous employment. Provided active myocarditis does not recur there is no reason for believing these results to be temporary. The outlook in most cases has been radically altered.

\section{Cardiac Trauma}

Surgical treatment for cardiac trauma is seldom required in this country. However, experiences in two world wars and more recently in India have shown that wounds of the heart are not invariably fatal. Elkin (I94I) and Harkin (1946) reviewed the treatment of wounds and removal of foreign bodies and their success in these procedures has put this type of surgery on a firm basis. For those cases reaching hospital, transfusion and the relief of cardiac tamponnade by pericardial aspiration are indicated, but continued bleeding calls for exposure of the heart and suture of the wound.

\section{Myocardial Ischaemia}

In contrast to the successful treatment of deformities and mitral stenosis no great advance has been achieved in the alleviation of myocardial ischaemia by surgery. Despite a trial of many different procedures resection of the upper five thoracic sympathetic ganglia, if necessary on both sides, provides only symptomatic relief when active treatment is indicated.

The surgery of the heart is therefore in a phase of rapid development. Active experimental work and tentative clinical application are progressing and procedures for the treatment of aortic stenosis and regurgitation, atrial septal defect, pulmonary hypertension and aneurysms may soon be forthcoming. In the next decade a combination of intrathoracic and peripheral vascular surgery bids fair to constitute the speciality of cardiovascular surgery.

\section{A. J. P. Graham, M.B., F.R.C.S.}

\section{BIBLIOGRAPHY}

ABBOTT, M. E. (1936), Atlas of Congenital Heart Disease, American Heart Association.

ALlen, D. S., and GRAHAM, E. A. (1922), f. Amer. med. Ass., $79,1028$.

BLALOCK, A. (1946), Ann. Surg., 124, 879.

BROCK, R. C. (1948), Brit. med. f., i, 1121 .

CUTLER, E. C., and BECK, C. S. (1929), Arch. Surg., 18, 403. ELKIN, D. C. (1941), Ann. Surg., 114, 169.

GROSS, R. E. (1951), Ann. Surg., 134, 753.

HARKIN, D. E. (1946), Surg. Gynec. Obstet., 83, 117.

SELLORS, T. H. (1948), Lancet, i, 988.

SOUTTAR, H. S. (1925), Brit. med. F., ii, 603.

TUBBS, O. S. (1944), Brit. F. Surg., 32, x.

The Book on

CHEMOTHERAPEUTIC AND ANTIBIOTIC DRUGS

IS

\section{NOW PUBLISHED}

The Postgraduate Medical Journal's series of articles on the present status of the Chemotherapeutic and Antibiotic Drugs commenced in August 1951, and finished in the March 1952 issue.

Published by

THE FELLOWSHIP OF POSTGRADUATE MEDICINE

60 Portland Place, London, W.I

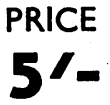

plus 3d. postage 